\title{
Predicting Altruistic Behavior and Assessing Homophily: Evidence from the Sisterhood
}

\author{
Michael J. Vernarelli
}

Rochester Institute of Technology

\begin{abstract}
The persistence of altruism throughout the evolutionary process has been explained by some on the basis of assortation, which requires the ability to detect dispositional altruism in others and voluntary interaction, resulting in altruism homophily. Numerous studies have identified the ability to detect dispositional altruism in strangers, but few have investigated this ability and altruism homophily in social networks. The purpose of this study is to provide additional evidence with regard to the ability to detect dispositional altruism among individuals who have repeated interactions in a collegiate social organization and the extent of altruism homophily. The results indicate that individuals possess an ability to predict dispositional altruism as measured by behavior in the dictator game and that this ability is a function of social closeness. However, the study does not support the hypothesis of an assortation process that results in altruism homophily.
\end{abstract}

Keywords: dispositional altruism; reciprocal altruism; homophily; assortation; dictator game

Citation: Vernarelli, Michael J. 2016. "Predicting Altruistic Behavior and Assessing Homophily: Evidence from the Sisterhood." Sociological Science 3: 889909.

Received: May 25, 2016

Accepted: June 30, 2016

Published: October 3, 2016

Editor(s): Jesper Sørensen, Gabriel Rossman

D0I: $10.15195 / \mathrm{v} 3 . a 38$

Copyright: (C) 2016 The Author(s). This open-access article has been published under a Creative Commons Attribution License, which allows unrestricted use, distribution and reproduction, in any form, as long as the original author and source have been credited. (1) (1)
$T^{X P L A n a t i o n s ~ o f ~ h o w ~ d i s p o s i t i o n a l ~ a l t r u i s m ~ i n ~ i n d i v i d u a l s ~ h a s ~ s u r v i v e d ~ t h e ~}$ E evolutionary process have appeared in the literature with increasing frequency in the last 30 or so years (Eshel and Cavelli-Sforza 1982; Frank 1988; Sober and Wilson 1998). The logic of natural selection leads to the conclusion that egoists should prevail in a competition for scarce resources because altruists, by definition, voluntarily part with resources, which would eventually lead to their extinction. One line of reasoning explaining the apparent anomaly of altruist survival posits that altruists will be able to outcompete egoists if altruists are able to group together for mutual benefit through an assortation process (Boorman and Levitt 1973; Peck 1992; Wilson and Dugatkin 1997). In order for this assortation process to occur, altruists must be able to identify fellow altruists. Once having identified similarly disposed individuals, the altruists then elect to interact for the mutual benefit of both parties. Egoists would have no alternative to interacting with each other (Macy and Skvoretz 1998).

This theory has two important implications, both of which are testable. First, because altruists are assumed to have superior innate abilities to detect their own kind, researchers should be able to identify these differential abilities in the general population. Second, the outcome of the assortation process should allow researchers to observe voluntary interpersonal groupings (homophily) on the basis of dispositional altruism.

Several researchers have asserted that humans do possess an innate ability to identify dispositional characteristics, including altruism in others (Frank 1988; Cosmides and Tooby 1992; Haselton and Funder 2006). Some research has evaluated judges' predictive ability of a target's altruism as indicated on survey instruments af- 
ter viewing videotape (Brown, Palameta, and Moore 2003; Oda et al. 2009; Feinberg, Willer, and Keltner 2012), but much has focused on the prisoner's dilemma game as an indicator of altruistic (prosocial) behavior. ${ }^{1}$ Researchers have examined the ability of judges to identify cooperative behavior after interaction with the targets (Frank, Gilovich, and Regan 1993; Yamagishi, Kikuchi, and Kosugi 1999a; Brosig 2002; Sparks, Burleigh, and Barclay 2015), viewing videotape (Manson, Gervais, and Kline 2013; Vogt, Efferson, and Fehr 2013), and viewing photographs of the targets (Verplaetse, Vanneste, and Braeckman 2007; Yamagishi et al. 2003; KovácsBálint, Bereczkei, and Hernádi 2013).

Researchers have focused less attention on the dictator game, though it is recognized as a standard measure of altruistic behavior in experimental settings (Hoffman, McCabe, and Smith 1996; Camerer 2003). Feinberg et al. (2012) found that embarrassment signals an individual's prosociality in the dictator game. Fetchenhauer, Groothuis, and Pradel (2010) tested the ability of individuals to detect permanent cues to altruism based on an event-unrelated stimulus. They created silent videotapes of the targets, after which the targets played a version of the dictator game. The videotapes were then shown to a different group of judges. The researchers found that average predictions correlated with actual decisions better than chance.

While the literature on the ability to predict dispositional altruism in one-off encounters is robust, there has been much less attention given to assessing such predictive ability in long-term relationships. Pradel, Euler, and Fetchenhauer (2009) investigated whether individuals were able to predict the level of altruism in others with whom they were familiar. Their study was conducted using German schoolchildren who were 10 to 19 years old in six school classes. The students were asked to play a hypothetical dictator game in which they were required to allocate an age-appropriate amount of money between themselves and an anonymous classmate. They were not given actual money to distribute at the time of the experiment. Rather, they indicated the amount that they would give to an anonymous student in their class. After playing the game, the students were asked to make predictions of the behavior of their classmates in the dictator game. One week later, half the student participants were randomly assigned the role of dictator and were then paired with participants from the other half, who served as the recipients. Payment was made on this basis. The researchers found support for the hypothesis that the students in the experiment were able to predict altruistic behavior greater than chance. They tested this two ways. First, they examined the correlation between an individual student's contribution to the anonymous student and the adjusted average prediction of the other students from the same class. Second, they analyzed the relationship between an individual student's contribution and the adjusted prediction of another student in the class (a dyad). The researchers also found that students who identified each other as friends or who indicated they disliked one another had more accurate predictions than those students who had mutually identified each other as likeable. In dyads in which the students had no opinion about one's partner, predictive ability was no better than chance.

In contrast to a rich literature on the ability of individuals to predict dispositional altruism, there has been relatively little evidence presented that individuals assort along the dimension of dispositional altruism. Sheldon, Sheldon, and Osbaldiston 
(2000) found a marginal correlation of dispositional altruism among participants who had self-selected in groups for purposes of the study. In the Pradel et al. (2009) study, the researchers found that the students in their experiment did assort themselves along the dimension of altruism-i.e., altruistic students tended to have altruistic classmates as friends, and egoistic students tended to have egoistic classmates as friends. They tested this by examining the correlation between dictator contributions of individual students mutually identified as friends.

An alternative approach to the role of assortation of similarly disposed individuals in the evolutionary process is based on the idea of reciprocal altruism (Trivers 1971; Dawkins 1976). In this view, humans possessing a propensity towards prosocial behavior survive extinction as a result of discriminating behavior in multiple encounters with others. They display a tit-for-tat strategy (Axelrod 1984) in which initial altruistic behavior is not repeated if not reciprocated by the interaction partner on subsequent encounters. Van Lange, Klapwijk, and Van Munster (2011) found that the anticipation of future interaction causes egoists to act more prosocially.

Simpson et al. (2014) argued that an underlying reciprocity approach to explaining prosocial behavior will lead to two very different outcomes than those predicted by Pradel et al. (2009). First, because the expectation of a long-term relationship will trump the significance of dispositional altruism (Parks and Rumble 2001; Rusbult and Van Lange 2003; Van Lange et al. 2011), widespread altruism homophily will not be manifested in the general population. Any altruism homophily may be an incidental result if individuals who are dispositionally altruistic are drawn to the same foci (Feld 1982), as homophily along other dimensions (e.g., ethnicity, age, race, income, sex) has been widely observed (McPherson, Smith-Lovin, and Cook 2001). Second, although the predictive ability to identify altruistic behavior in single encounters with strangers has been well documented, that ability may be blunted in long-term friendships. Individuals may project their own disposition onto their friends' behavior (Ross, Greene, and House 1977; Krueger and Clement 1994; Fetchenhauer and Dunning 2006; Simpson and Willer 2008), with the result being that individuals have limited insight into the dispositional altruism of their friends.

Simpson et al. (2014) conducted three studies to test their hypotheses: (1) friendships will exhibit altruism homophily, and (2) individuals are able to predict their friends' prosociality towards strangers. In their first study, students were sent email invitations and upon agreeing to participate by completing a survey were asked to invite additional participants (respondent-driven sample) with whom they had regular contact. The survey included the standard measure of social value orientation (SVO), considered a widely accepted measure of dispositional altruism (Van Lange 1999). After categorizing the participants as either egoists, altruists, or unclassifiable, the researchers developed four logistic regression models. The first two models predicted whether a participant was an altruist or an egoist based on the SVO, allowing the researchers to detect any preference for associating with altruists and the existence of dispositional homophily. The third model tested for sex homophily, and the fourth model tested for the relationship between dispositional homophily and frequency of interaction between participants (measuring intensity of friendship). The results of the regression analysis showed no altruism homophily; 
altruistic participants were no more likely to have an altruistic friend than egoists. Only sex homophily was statistically significant.

The second study was undertaken because of the possibility that altruism homophily may only manifest itself where there is a high degree of mutual interaction and/or more homogeneity with respect to sociodemographic characteristics. The researchers selected a large collegiate sorority from which to draw participants. Participants were required to complete a survey that included the same SVO items as the first study. The survey also required participants to identify other members of the sorority with whom they had varying degrees of social closeness and sisters who they identified as exhibiting publically observed altruism within the sorority. Again, regression models were developed to measure altruism homophily. The results were generally consistent with those of the first study. The participants were able to identify some altruists through their public behavior but showed no tendency to associate with them as friends. Furthermore, egoists demonstrated no tendency to be forced to associate with other egoists, as would be predicted by the altruism assortation model.

For the third study, initially recruited participants were required to bring a friend, and both would have the opportunity to earn money. Participants completed a survey that included the SVO items and played a hypothetical dictator game and the trust dilemma game. Participants were matched in dyads with a random participant with whom they were not familiar and were asked to make predictions regarding the behavior of their partner in the dyad and their friend's decisions. The researchers found that while participants' predictions were strongly influenced by their own behavior, they were unable to predict others' behavior better than chance. Furthermore, consistent with the findings of the other two studies, there was no support for the hypothesis of altruism homophily.

\section{Overview of the Study}

The current study was undertaken to investigate the existence of altruism homophily and ability of individuals to predict friends' dispositional altruism towards strangers in a genuine social group in a natural setting. Although research in the area of predicting dispositional altruism in one-time encounters has been extensive, as the literature review in the previous section indicates, examination of predictive behavior of dispositional altruism by members of social groups has been rather limited. Investigation into the existence of altruism homophily in social groups has likewise been limited. Only two studies, Pradel et al. (2009) and Simpson et al. (2014), have investigated both questions. The results of those studies appear to be diametrically opposed. Pradel et al. found that members of the social group (school classmates) were able to predict other members' dispositional altruism better than chance and affirmed the existence of altruism homophily, while Simpson et al. found neither predictive ability nor altruism homophily in the social group (collegiate social sorority) they studied.

The current study was designed to provide additional evidence on these two questions. The study investigates predictive ability of dispositional altruism and altruism homophily in a collegiate social sorority, as was done in the second of 
Simpson et al.'s three studies. The study also examines behavior in the dictator game as the measure of dispositional altruism, as was done in the Pradel et al. study and the third of Simpson et al.'s three studies. Thus, the study will offer results that are juxtaposed to those of both Pradel et al. and Simpson et al.

The study contains design features that improve upon the Pradel et al. and Simpson et al. studies as follows:

(1) In playing the dictator game in Pradel et al. and Simpson et al.'s third study, the student participants in those studies did not actually allocate money between themselves and anonymous students during the experiment. Rather, they had to make hypothetical decisions, with the payment mechanism being activated later. Furthermore, when payment was made later, not all participants received what they had decided to keep for themselves as dictators; one-half were randomly selected to be recipients. Numerous studies have shown that individuals discount both delayed and probabilistic rewards compared to receiving a certain amount in the present (Kahneman and Tversky 1979; Rachlin et al. 1986; Raineri and Rachlin 1993; Madden et al. 2003; Green and Myerson 2004). In the current study, participants were given money during the experiment itself and were required to allocate it between themselves and an anonymous student. All participants played the role of dictator and received the dictator's payoff.

(2) In Pradel et al., there is the issue of anonymity along two dimensions. First, the perception of anonymity by participants making the dictator decision was potentially compromised. Participants sat in a circle while making their decision. The authors admit that the environment may have been considered partly public, thus triggering intuitive or affective behavior regarding reputational consequences (Burnham and Hare 2007). Prior research has shown that removing anonymity affects contributions in economic games (Andreoni and Petrie 2004). A number of studies have found that eyespots observed during the decision-making process have increased the mean value of the dictator's contribution and/or the percentage of participants making dictator contributions (Haley and Fessler 2005; Rigdon et al. 2009; Nettle et al. 2013).

Second, the anonymity of the recipients was potentially compromised because participants were told that the dictator's contribution would be made to someone in the class. Consequently, the prospective recipient was not someone unknown to the dictator. Prior research has shown that reducing social distance increases contributions in the dictator game (Hoffman et al. 1996).

The current study is designed to enhance the perception of anonymity along both dimensions. Participants made their dictator decisions in complete privacy, outside the presence of any other participants or members of the research team. Recipients were not participants in the study and were completely anonymous to the participants as well as members of the research team.

(3) In Simpson et al.'s second study of the prediction of dispositional altruism and homophily in the collegiate social sorority, the researchers acknowledge that it was costless for the participants to give altruistic responses to the survey measure. In the current study, the participants (members of a collegiate social sorority) had immediate and costly consequences to their decisions in the dictator game. Additionally, the predictions of altruistic behavior focused on identifying those members 
who behaved prosocially on behalf of the sorority ("up to five sisters who you feel sacrifice most on behalf of the sorority"). Social identity theory (Billig and Tajfel 1973) posits that there is an ingroup-outgroup bias in which ingroup members are treated preferentially over outgroup members as a result of reputation management. Consequently, the sorority participants in the Simpson et al. study were predicting not only dispositional altruism but behavior influenced by the target's reputation management as well. In the current study, the predicted prosocial behavior was directed towards outgroup members (anonymous nonsorority members). This behavior more accurately reflects underlying dispositional altruism.

The hypotheses tested are as follows:

I. Members of a collegiate social organization are able to predict each other's dispositional altruistic behavior.

II. Members assort themselves along the dimension of dispositional altruism (altruism homophily).

III. Accuracy of dispositional altruism predictions is a function of the judge's perception of social closeness with the targets.

IV. Altruists are more accurate than egoists in predicting dispositional altruism.

\section{Methods}

The study was conducted with members of a social sorority at a large private university in the Northeastern United States. Prior to conducting the experiment, the researcher met with a small focus group of members (sisters) of the sorority to develop descriptions of measures of social closeness, consistent with prior research (Pierce et al. 1997), that the participants in the experiment would use to characterize their relationships with other participants. Three categories of social closeness were developed and used in the experiment: Category 1 Sister (least social closeness), Category 2 Sister (intermediate level of social closeness), and Category 3 Sister (highest degree of social closeness). Descriptions of each of the categories are contained in Appendix A of the online supplement.

Members of the sorority were invited to participate in the experiment via email. They were told that the experiment would take about an hour and a half and would be conducted in the great room of their sorority house. Each participant was told she would be paid a $\$ 10$ participation fee upon successful completion of the experiment.

A research team (author and two research assistants) conducted the experiment. Thirty sorority sisters participated in the experiment. At the beginning of the experiment, the research team distributed lanyards with a number attached and instructed the participants to wear the lanyard throughout the experiment. Participants were identified by their assigned number to maintain their anonymity to the research team and protect the confidentiality of their decisions and the information they provided during the experiment. Each participant was handed a clipboard containing an envelope with 10 one-dollar bills, descriptions of the three categories of social closeness, and a rating sheet. 
The participants were told the following. They would be playing a version of the dictator game, although it was not identified as such, and predicting the decisions of the other participants. As a condition of their participation, they could not discuss their decisions, ratings, or predictions during or after the experiment. After hearing this overview, they were required to sign an informed consent statement and the formal experiment began.

The research team read aloud the social closeness descriptions while the participants followed along on their handouts. Each participant was then asked to stand one at a time and face the group so her number was clearly visible. She was told not to speak or make any gesture. When a participant stood the others rated the degree of social closeness they perceived with her by checking a box next to her number indicating either Category 1, Category 2, or Category 3. After all participants had rated the degree of social closeness with the other participants, the research team explained how the dictator game would work. The participants would decide how many one-dollar bills they would take for themselves to keep and how many to leave in the envelope. The research team would have no way of connecting the amounts taken from and left in the envelope with the identity of the participants. The envelope would be given to an anonymous student who was not a member of the sorority. The anonymous student would not know from whom or where the money was coming. The student would also be anonymous to the research team. The research team did not disclose the actual method of distribution to the anonymous students. This method is described in Appendix B of the online supplement.

Next, the research team told the participants to find a private place in the sorority where no one could see how much money was being taken out of the envelope and how much was left in it. Once all the participants had completed this task and had returned the envelopes to the research team, they were asked to stand one by one as before, during which time the other participants wrote down their predictions of how much that participant had retained and how much was left in the envelope. Again, the participants were instructed not to speak or otherwise gesture during this part of the experiment. The participants submitted their rating sheets to the research team and were paid their participation fee, thus completing the experiment.

\section{Results}

The decisions and ratings of 29 participants were analyzed. One participant was eliminated from the data set because she had not completely filled out the rating sheet. The participants contributed an average of $\$ 3.97$ to the anonymous student. Table 1, showing the frequency of each amount contributed, is given below.

The distribution seems consistent with past results from the dictator game, with the exception of the fact that four participants (14\%) contributed the entire amount to the anonymous student. The average amount predicted to be given to the anonymous student was $\$ 4.52$, slightly more than the actual amount, demonstrating that the "better than average" effect was not present (Fetchenhauer and Dunning 2009). This difference was not statistically significant [t(29) $=-1.04]$. 
Table 1: Frequency distribution of dictator contributions.

\begin{tabular}{lccccccccccc}
\hline Amount Contributed & $\$ 0$ & $\$ 1$ & $\$ 2$ & $\$ 3$ & $\$ 4$ & $\$ 5$ & $\$ 6$ & $\$ 7$ & $\$ 8$ & $\$ 9$ & $\$ 10$ \\
\hline Frequency & 5 & 3 & 3 & 1 & 3 & 9 & 1 & 0 & 0 & 0 & 4 \\
\hline
\end{tabular}

\section{Hypothesis I: Members of a Collegiate Social Organization Are Able to Predict Each Other's Dispositional Altruistic Behavior}

The first hypothesis tested is that participants are able to predict the

altruistic behavior of their fellow participants. However, as has been noted in previous studies-e.g., Pradel et al. (2009)—-the fact that the experiment requires every participant to predict the behavior of every other participant renders the predictions nonindependent. The data analysis adjusted for this phenomenon by using a method devised by Warner, Kenny, and Stoto (1979). A description of this adjustment is contained in Appendix $\mathrm{C}$ of the online supplement.

The predictive ability regarding identification of altruistic behavior was first tested by analyzing the correlation between the actual amount contributed by a participant (target) and the adjusted average prediction by the other 28 participants (judges). The correlation was positive and statistically significant $(\mathrm{r}=0.42, \mathrm{p}=0.01$, one-tailed $)^{2}$.

The second test of predictive ability examined the correlation between amount contributed and adjusted prediction of amount contributed using a dataset in which the unit of observation was the individual participant. This dataset contained 812 dyads $(29 \times 28)$ in which each participant predicted the amount contributed by each of the other 28 participants. Again, the correction for the nonindependence of observations was applied. The correlation was statistically significant $(\mathrm{r}=0.18, \mathrm{p}<$ 0.001 , one-tailed). Thus, the data analysis supports the hypothesis that members of the social organization can predict the dispositional altruism of other members better than chance.

\section{Hypothesis II: Members Assort Themselves along the Dimension of Dispositional Altruism}

The second hypothesis is that participants who identify each other as socially close assort themselves along the dimension of altruism. The study analyzed dyad level datasets in which the participant and her partner identified each other as Category 3 or in which the participant and her partner identified each other as Category 2. As noted previously, Category 3 dyads were defined as exhibiting the highest degree of social closeness, while Category 2 dyads exhibited an intermediate level of social closeness. Of the 812 dyads, there were 88 dyads (44 unique pairings) in which each participant rated her partner Category 3 and 128 dyads (64 unique pairings) in which each rated her partner Category 2.

Analysis of the data did not support this hypothesis. The correlation between the participant's and her partner's actual decisions showed a negative correlation for Category 3 dyads $(r=-0.23)$. The negative correlation indicates a trend of 
Table 2: Correlation of adjusted judge's prediction with target's contribution.

\begin{tabular}{lccc}
\hline Category Rated by Judge & N & $\begin{array}{c}\text { Correlation } \\
\text { Coefficient }\end{array}$ & $\begin{array}{c}\mathrm{p} \text {-value } \\
\text { (one-tailed) }\end{array}$ \\
\hline 1 & 417 & 0.12 & $<0.01$ \\
2 & 261 & 0.16 & $<0.01$ \\
3 & 134 & 0.34 & $<0.01$ \\
\hline
\end{tabular}

altruist-egoist pairings in the dyads instead of altruist-altruist or egoist-egoist pairings that would result in a positive correlation coefficient consistent with the presence of altruism homophily. For Category 2 dyads, the correlation coefficient was likewise negative. $(r=-0.02)$. The near-zero value is indicative of randomness in the pairings in the pool of altruists and egoists.

\section{Hypothesis III: Accuracy of Predictions Is a Function of Judge's Perception of Social Closeness to the Target}

The third hypothesis tested whether the judge's perception of the degree of social closeness is positively related to the accuracy of the predictions (measured by the magnitude of the correlation coefficient). Individuals are typically most familiar with those to whom they are most close (Mashek, Aron, and Boncimino 2003). Consequently, one would hypothesize that greater familiarity would lead to a higher level of understanding of the familiar individual's dispositional traits, including altruism. For this analysis, the 812 dyads were divided into three subsamples according to the category rating the judge assigned to the target. The judge's adjusted prediction was then correlated with the target's actual contribution. The results are given in Table 2.

The dyads in which judges rated their relationship as most socially close with targets (Category 3) had the largest correlation coefficient. For dyads in which the judges rated their relationship at an intermediate level of social closeness (Category 2) with targets, the correlation was weaker but still statistically significant. Finally, for those dyads in which judges rated their relationship as the least level of social closeness (Category 1 ) with targets, the correlation was weakest but still significantly different from zero. Using the Fisher r-to-z transformation, the difference between the correlation coefficients for Category 1 and Category 3 was significant at the 0.05 level. The data support the hypothesis that the judge's perception of social closeness is related to more accurate predictive ability.

A caveat to the interpretation that the magnitude of the correlation coefficient measures true predictive ability is that the analysis did not control for a false consensus effect (Ross et al. 1977). Studies have shown that individuals rely heavily on self-related knowledge despite the availability of other relevant information (Krueger and Clement 1994). However, if an individual believes that a target person's behavior is similar to his or her own, and the target person does in fact manifest similar behavior, this would lead to accurate predictions without having true independent predictive ability (Dawes and Mulford 1996). This has been 
Table 3: Regression of judge's prediction on target's contribution and judge's contribution.

\begin{tabular}{lccccc}
\hline Category Rated by Judge & & \multicolumn{2}{c}{ Target's Contribution } & \multicolumn{2}{c}{ Judge's Contribution } \\
& $\mathrm{N}$ & Coefficient & $\mathrm{p}$-value & Coefficient & $\mathrm{p}$-value \\
\hline 1 & 417 & 0.10 & 0.01 & 0.28 & $<0.01$ \\
2 & & $(0.04)$ & & $(0.04)$ & \\
& 261 & 0.11 & 0.05 & 0.25 & $<0.01$ \\
3 & & $(0.06)$ & & $(0.06)$ & \\
& 134 & 0.27 & $<0.01$ & 0.16 & 0.04 \\
\hline
\end{tabular}

shown to be true in close relationships (Schul and Vinokur 2000). In the analysis undertaken above, the potential for a false consensus effect exists because the dyads by definition reflect close relationships (of varying degrees). The study followed the approach (Kenny and Acitelli 2001) adopted in both Pradel et al. (2009) and Simpson et al. (2014) to simultaneously measure the false consensus effect and the judge's true ability to identify the target's dispositional altruism. Regression equations were developed for each of the dyad category subsamples, with the judge's prediction as the dependent variable and the target's actual contribution and the judge's actual contribution as independent variables. The results are given in Table 3.

The results of the regressions indicate a false consensus effect that was stronger in those dyads in which the judge rated the target either Category 1 or Category 2. In those cases, the regression coefficient for the judge's contribution is at least twice as large as the coefficients for the target's contribution. But in each case, the coefficient for the target's contribution is statistically significant. This implies that judges are able to predict the target's actual contribution better than chance after the false consensus effect has been controlled for. The comparison of the magnitude of the coefficients is reversed for those dyads in which the judge rated the relationship with the target as Category 3. There, the coefficient for the targets' contribution is larger and has a lower p-value than the coefficient of the judge's contribution. The rank ordering of the regression coefficients for the target's contribution for the three categories is consistent with the rank ordering of the correlation coefficients from Table 2. These results are consistent with the hypothesis that the greater the degree of social closeness perceived by the judge, the more accurate the prediction of the target's contribution.

The distortion in true accuracy caused by the false consensus effect (perceived homophily) can be removed by adjusting the correlation coefficients in accordance with the methodology suggested by Kenny and Acitelli (2001). First, the objective similarity of the judge's contribution and the target's contribution for each dyad subsample must be determined through correlation. The results are given in Table 4.

The correlation coefficient of objective similarity is multiplied by the coefficient of the judge's contribution from the regression equation reported in Table 3 . This measures the increment due to the false consensus effect. Then, the product is 
Table 4: Objective similarity of judge's and target's contributions.

\begin{tabular}{lccc}
\hline Category Rated by Judge & N & $\begin{array}{c}\text { Correlation } \\
\text { Coefficient }\end{array}$ & $\begin{array}{c}\text { p-value } \\
\text { (one-tailed) }\end{array}$ \\
\hline 1 & 417 & -0.00 & 0.48 \\
2 & 261 & -0.02 & 0.39 \\
3 & 134 & -0.15 & 0.05 \\
\hline
\end{tabular}

subtracted from the correlation coefficient from Table 2. This gives true accuracy. The results are given in Table 5 .

Because the objective similarity shows a negative correlation for each category of perceived social closeness, the removal of the false consensus effect serves to increase true accuracy. However, because the magnitude of the effect is negligible for those dyads in which the judge rated the target either Category 1 or Category 2 , there is no effect on overall accuracy. For Category 3, true accuracy is slightly greater after the false consensus effect has been removed. After making adjustments to reflect true accuracy, there is no change in the original conclusion regarding the relationship between predictive accuracy and perceived closeness by the judge.

\section{Hypothesis IV: Altruists Are More Accurate than Egoists in Predicting Dispositional Altruism}

In order to test the hypothesis that altruists are more attuned to detecting dispositional altruism in others, individual accuracy rates (correlation between an individual judge's predictions and the other participants' contributions) were calculated. Ten participants (34\%) had individual accuracy rates that were positive and significant at the 0.05 level $(0.47 \geq \mathrm{r} \geq 0.32)$, eleven (38\%) had individual accuracy rates that were positive and insignificant, and the remaining eight (28\%) had individual accuracy rates that were negative and insignificant. The individual accuracy rates were then correlated with the amount contributed by that judge. The individual accuracy rates were also correlated with the number of Category 3 ratings the judge assigned to each of the other 28 participants and with the number of Category 3 ratings the judge received from the other 28 participants. The results are given in Table 6.

The results do not support the hypothesis that altruists have more accurate predictions about others' dispositional altruism. The negative correlation coefficient indicates the opposite, though it is not statistically significant. The correlation between the number of Category 3 ratings the judge assigned to other participants and the judge's individual accuracy rating is positive but insignificant, and the correlation between the judge's individual accuracy rating and the number of Category 3 ratings the other participants assigned to that judge is positive and statistically significant. These findings are consistent with the result from testing Hypothesis III; perceived social closeness is positively related to accuracy of prediction. 
Table 5: Accuracy of prediction by degree of social closeness perceived by judge.

\begin{tabular}{lcccc}
\hline Category Rated by Judge & N & $\begin{array}{c}\text { Correlation } \\
\text { Coefficient } \\
\text { from Table 2 }\end{array}$ & $\begin{array}{c}\text { Increment } \\
\text { due to False } \\
\text { Consensus Effect }\end{array}$ & $\begin{array}{c}\text { True } \\
\text { Accuracy }\end{array}$ \\
\hline 1 & 417 & 0.12 & -0.00 & 0.12 \\
2 & 261 & 0.16 & -0.00 & 0.16 \\
3 & 134 & 0.34 & -0.02 & 0.36 \\
\hline
\end{tabular}

\section{Discussion}

This study was designed to test a similar set of hypotheses that were tested by Pradel et al. (2009) and Simpson et al. (2014) to determine whether their results were reproducible using participants from a collegiate social organization in which members were familiar with one another in varying degrees. Pradel et al. and Simpson et al. examined two overarching hypotheses: (1) Can individuals predict the degree of dispositional altruism in their friends? and (2) Is there evidence that this ability results in altruism homophily (assortation)? The Pradel et al. and Simpson et al. studies reported dramatically different findings. This study was able to provide additional evidence with respect to those conflicting results. The bottom line is that some of the results were consistent with those obtained by Pradel et al., while others were consistent with the Simpson et al. results. Similarities and differences among the three studies are discussed below.

The current study and the Pradel et al. research shared some common design features. Both studies had members of genuine social groups (school classes in the case of Pradel et al. and a collegiate social sorority in this study) playing the dictator game and then attempting to predict the behavior of other members of the group. In both studies, participants were grouped together in what could be perceived as public settings. Research has shown that prosocial behavior can be affected by subtle cues in economic games (Haley and Fessler 2005). In Pradel et al., participants made their decisions in the presence of other participants and were aware that their dictator contribution would be received by another participant in the study. The fact that participants were uncertain as to whether they would receive the amount decided upon as dictator or would be a recipient further complicated the decision-making environment. The research design of the current study eliminated these confounding influences by having the participant make her decision in complete privacy to an anonymous individual who was not part of the study. The participant received the amount she decided to keep as dictator immediately with complete certainty. However, because participants were in a public setting prior and subsequent to making the dictator decision, the possibility that reputation management cues played a role in the decision cannot be eliminated.

Behavior of the participants in their dictator game decisions in Pradel et al. and the current study was quite similar. Pradel et al. found that the students in their study contributed an average of $37.3 \%$ of the total amount to the anonymous classmate. Analysis of data in this study found that participants contributed 39.7\% 
Table 6: Correlation of individual accuracy rates and selected variables.

\begin{tabular}{lcc}
\hline & $\begin{array}{c}\text { Correlation } \\
\text { Coefficient }\end{array}$ & $\begin{array}{c}\text { p-value } \\
\text { (one-tailed) }\end{array}$ \\
\hline Amount Contributed by Judge & -0.24 & 0.11 \\
Category 3 Ratings Given by Judge & 0.27 & 0.08 \\
Category 3 Ratings Received by Judge & 0.42 & 0.01 \\
\hline
\end{tabular}

of the total amount to an anonymous student. It should be noted that Pradel et al. excluded those participants who had contributed greater than $50 \%$ of the amount to be allocated (3.9\% of the participant pool) from the subset of data that they analyzed because they could not be sure that the participants understood the instructions. This study, on the other hand, found that $17.2 \%$ of contributions exceeded $50 \%$ of the total amount. Those contribution decisions were retained because the participants had actually made the monetary allocations during the experiment (contrasted with hypothetical decisions in Pradel et al.).

A difference in the results between this study and the Pradel et al. study was the relationship of the judges' predictions to the actual decisions. Pradel et al. found evidence of the "better than average" effect in their study-i.e., participants tended to underestimate the level of altruism in their classmates. Analysis of the data in this study found the opposite: participants slightly overestimated the level of altruism in their fellow participants, though the difference was not statistically significant.

Pradel et al. and this study tested the hypothesis that individuals are able to predict altruistic behavior and the results were remarkably consistent. Both analyzed predictive behavior from two perspectives: (1) the average of all judges' predictions for an individual target and (2) the predictions made by individual judges for individual targets at the dyad dataset level. The correlation coefficient from the analysis comparing actual decisions with the average adjusted prediction of the judges was 0.39 in the Pradel et al. study and 0.42 in this study. Both were statistically significant. In the analysis of individual predictions in the dyad dataset, the correlation coefficient was 0.18 in this study as compared with 0.21 (boys and girls combined) and 0.16 (with sex partialed out) in Pradel et al. All were statistically significant. Using the Fisher r-to-z transformation, the test for differences between comparable correlation coefficients in Pradel et al. and this study was not significant at the 0.05 level.

Simpson et al. analyzed individuals' predictive ability of friends' decisions in the dictator game in their third study. They regressed the judge's prediction on the target's actual contribution in the game and other control variables. They found that the coefficient of the target's actual contribution was insignificant, leading to their conclusion that the participants in the study were unable to predict the behavior of their friends in the dictator game better than chance, in contrast to the findings in Pradel at al. and this study.

A major finding of Pradel et al. was evidence of the assortation of altruists. When analyzing the relationship between actual contributions of participants who had mutually identified themselves as friends, they reported a correlation coefficient 
of 0.16 (with sex partialed out) that was statistically significant. Pradel et al. asserted that this result provided evidence of altruism homophily. Comparable analysis in the current study calculated the correlations between the actual decisions of those participants in dyads that mutually identified as having the most socially close relationship (Category 3) and between the decisions of participants who mutually identified as having a relationship with an intermediate level of social closeness (Category 2). The results indicated that the correlation coefficients for actual decisions by both Category 3 and Category 2 dyadic partners were negative. These results indicate that there was no evidence of altruism homophily in either the Category 3 or Category 2 relationships. This finding is in opposition to what Pradel et al. reported. In all three of the Simpson et al. studies, the researchers found no evidence of altruism homophily.

This study's results with respect to accuracy of prediction and degree of social closeness before adjustment for the false consensus effect were consistent with those of Pradel et al. They reported correlation coefficients for the participant's actual contribution and the judge's prediction of 0.34 for those participants expressing mutual friendship and 0.11 for those mutually indicating "liking." The current study found remarkably similar results: correlation coefficients of 0.34 for those judges rating the targets as Category 3, 0.16 for targets rated as Category 2, and 0.12 for targets rated as Category 1.

Pradel at al., Simpson et al., and the current study all applied a methodology based on Kenny and Acitelli (2001) to identify the simultaneous measurement of predictive accuracy and the false consensus effect (Ross et al. 1977). This involved regressing the judge's prediction on the target's actual contribution (reflecting true accuracy) and the judge's actual contribution (reflecting bias). All three studies found evidence of a false consensus effect, with Pradel et al. reporting coefficients for the judge's actual contribution of 0.58 for mutually identified friends and 0.40 for mutual "liking" dyads and Simpson et al. reporting a coefficient of 0.51 for their Model Two version of the dictator game predictions in friend dyads. The current study found coefficients with smaller magnitudes: 0.28 for Category 1 dyads, 0.25 for Category 2 dyads, and 0.16 for Category 3 dyads. This indicates a less powerful false consensus effect than was found in either Pradel et al. or Simpson et al. (the regression coefficients in all three studies were statistically significant).

Both Pradel et al. and this study used the regression results to adjust the correlation coefficients to reflect true accuracy (Simpson et al. did not present correlation analysis and found the regression coefficient for target's actual contribution in their study of dictator game predictions [Study 3] to be insignificant). Because Pradel et al. found evidence of altruism homophily (objective similarity of participants in the friend and "liking" dyads), true accuracy was lower after adjustment. Pradel et al. reported true accuracy in the friend dyads as 0.25 and the "liking" dyads as 0.08 . This contrasts with the current study, in which true accuracy for Categories 1 and 2 dyads was unaffected ( 0.12 and 0.16 , respectively) and was slightly higher Category 3 dyads (36) after adjustment.

Pradel et al. indicate that they computed individual accuracy rates (correlations between judge's prediction and target's actual contribution) but did not use them in the analysis. Simpson et al.'s study design did not allow for the computation of 
individual accuracy rates. The current study computed individual accuracy rates and used them to test the hypothesis that altruists are more accurate than egoists in predicting dispositional altruism. The results suggest that altruists are no better than egoists in predicting dispositional altruism; the negative sign of the correlation coefficient indicates the opposite, although it is not significant. Rather, the results indicate that the number of targets who perceive a socially close relationship with the judge is positively correlated with the judge's predictive accuracy.

\section{Conclusion}

The persistence of dispositional altruism has been a puzzle for which natural selection does not have a ready answer. One line of reasoning that has been proposed is the assortation of altruists. (Frank 1988; Wilson and Dugatkin 1997). A simplified version posits that if altruists prefer interaction with other altruists, synergistic benefits would be realized. Egoists who are identified as such would be avoided as interaction partners and would consequently be limited in their interactions to the pool of other egoists.

An alternative view distinguishes between one-time and repeated encounters. For one-time interactions, the ability to detect dispositional altruism is of paramount importance, but this is not so in repeated encounters or where a relationship is expected to be ongoing. In the latter cases, reciprocal altruism takes precedence (Trivers 1971; Axelrod 1984). Altruistic behavior is reinforced only if it is reciprocated. Dispositional egoists have an incentive to modify their behavioral inclination in repeated encounter relationships with altruists.

These two approaches have very different empirical implications that are testable. According to assortation theories, altruists must be able to identify other altruists and then assort to reap benefits. As a result, we should be able to observe predictive ability with respect to dispositional altruism as well as altruism homophily in the general population. Reciprocal altruism theories would predict that because of the relative unimportance of the predictive ability of friends' dispositional altruism in long-term relationships, we would not necessarily observe its presence in such social networks. By implication, instances of altruism homophily would be chance occurrences.

As indicated earlier in this article, there has been much evidence presented in the literature that individuals possess an ability to identify dispositional altruism in strangers but much more limited evidence of that predictive ability among friends in social networks. Pradel et al. (2009) is notable in this regard, while Simpson et al. (2014) offers contrary evidence that individuals in long-term relationships have no special ability to predict the dispositional altruism of their partners.

Additionally, Pradel et al. found evidence of altruism homophily in the social group (German secondary school children) studied, while Simpson et al. found no altruism homophily in the groups (college social sorority and student friendships) they studied. Thus, the results of these two studies stand in stark contrast to one another.

The current study was undertaken to provide additional evidence on these questions. The study found that members of a social network (college social sorority) 
could predict dispositional altruism better than chance in their fellow members. Furthermore, the results indicated that accuracy of predictive ability was a function of social closeness; individuals who perceived more socially close relationships were more accurate in their predictions.

However, somewhat paradoxically, the study found no evidence of any resulting altruism homophily. Instead, the results indicate that there was a negative, but insignificant, correlation of the dispositional altruism in dyads in which partners mutually identified as having the most socially close relationships with one another and in dyads in which partners mutually identified as having an intermediate level of social closeness. In another sense, finding a lack of altruism homophily among the study participants is not at all surprising given that they have, of their own volition, sought membership in the group. Yamagishi, Jin, and Kiyonari (1999b) argued that ingroup membership creates an expectation of generalized reciprocity, what they termed bounded generalized reciprocity. An individual expects favorable treatment from other group members as a condition of group membership. In such an environment, strong dyadic social ties can develop without concern for the dispositional altruism of one's interaction partner. Consequently, assortation along dimension of dispositional altruism would occur by chance.

Taken together, the study's main results showing a weak ability to detect dispositional altruism by members of a social network but the absence of altruism homophily are more supportive of a reciprocal altruism approach to the evolutionary puzzle of the persistence of altruism. However, it should be emphasized that the study did not find positive evidence of reciprocal altruism. The results indicate that individuals in a social organization, whether altruists or egoists, possess differential abilities with respect to a "personality judgment instinct" (Haselton and Funder 2006). Predictive accuracy was unrelated to the dispositional altruism of the judge but rather related to the number of individuals who perceived an intimate relationship with the judge. At least some altruists and egoists possess an innate ability to identify dispositional altruism, but that doesn't inhibit relationship formation with others of a different dispositional type (Van Lange et al. 2011). Rather, it apparently renders individuals more closely attuned to the feedback they receive in the tit-for-tat behavioral response mechanism suggested by Axelrod (1984).

It is possible that egoist-altruist parings offer a counterintuitive, as yet unidentified synergistic benefit. Prior "opposites attract" research has identified benefits for high extraversion-low extraversion parings (Kristof-Brown, Barrick, and Stevens 2005) and submissive-dominant pairings (Dryer and Horowitz 1997). This is an area for further investigation.

The correlation between perceived social closeness and predictive accuracy is suggestive of a causal nexus running from predictive ability to the number of intimate relationships formed. People imbued with the ability to detect dispositional altruism and egoism perhaps form more close relationships because they are able to readily identify this trait and interact differentially with each personality type. The result is a mixture of altruist-altruist, altruist-egoist, and egoist-egoist relationships formed on a more or less chance basis according to the distribution of the "personality judgment instinct" trait in the general population. The aggregation of these relationships would manifest itself in the absence of altruism homophily. To 
borrow from Simpson et al.: "birds of different feathers cooperate together" to the extent that they recognize the different flocks.

\section{Notes}

1 Prosocial behavior is defined in this article as a behavioral outcome of dispositional or reciprocal altruism.

2 The null hypothesis, $\mathrm{r} \leq 0$, dictated use of the one-tailed test.

\section{References}

Andreoni, James, and Ragan Petrie. 2004. "Public Goods Experiment without Confidentiality: A Glimpse into Fund-Raising." Journal of Public Economics 88:1605-1623. http://dx. doi . org/10.1016/S0047-2727(03)00040-9

Axelrod, Robert. 1984. The Evolution of Cooperation. New York: Basic Books. http://dx. doi . org/10.1002/ejsp. 2420030103

Billig, Michael, and Henri Tajfel. 1973. "Social Categorization and Similarity in Intergroup Behaviour." European Journal of Social Psychology, 3: 27-55.

Boorman, Scott A., and Paul R. Levitt. 1973. "A Frequency-dependent Natural Selection Model for the Evolution of Social Cooperation Networks." Proceedings of the National Academy of Sciences of the USA 70:187-189. http://dx . doi .org/10.1073/pnas .70.1.187

Brosig, Jeannette. 2002. "Identifying Cooperative Behavior: Some Experimental Results in a Prisoner's Dilemma Game." Journal of Economic Behavior and Organization 47:275-290. http://dx.doi.org/10.1016/S0167-2681(01)00211-6

Brown, William Michael, Boris Palameta, and Chris Moore. 2003. " Are There Nonverbal Cues to Commitment? An Explanatory Study Using the Zero-Acquaintance Video Presentation Paradigm." Evolutionary Psychology 1:42-69. http://dx .doi .org/10.1177/ 147470490300100104

Burnham, Terence C., and Brian Hare 2007. "Engineering Human Cooperation: Does Involuntary Neural Activation Increase Public Goods Contributions?" Human Nature 18:88-108. http://dx.doi.org/10.1007/s12110-007-9012-2

Camerer, Colin. 2003. Behavioral Game Theory: Experiments on Strategic Interactions. Princeton, NJ: Princeton University Press.

Cosmides, Leda, and John Tooby. 1992. “Cognitive Adaptation for Social Exchange." Pp. 163-228 in The Adapted Mind edited by Jerome H. Barkow, Leda Cosmides, and John Tooby. New York: Oxford University Press.

Dawes, Robyn M., and Matthew Mulford. 1996. "The False Consensus Effect and Overconfidence: Flaws in Judgment or Flaws in How We Study Judgment?" Organizational Behavior and Human Decision Processes 65:201-211. http://dx . doi .org/10.1006/obhd .1996.0020

Dawkins, Richard. 1976. The Selfish Gene. Oxford: Oxford University Press.

Dryer, D. Christopher, and Leonard M. Horowitz. 1997. “When Do Opposites Attract? Interpersonal Complementarity versus Similarity." Journal of Personality and Social Psychology 72:592-603. http://dx.doi.org/10.1037/0022-3514.72.3.592

Eshel, Ilan, and L. L. Cavalli-Sforza. 1982. "Assortment of Encounters and Evolution of Cooperativeness." Proceedings of the National Academy of Sciences 79:1331-1335. http: //dx.doi.org/10.1073/pnas.79.4.1331 
Feinberg, Matthew, Robb Willer, and Dacher Keltner. 2012. "Flustered and Faithful: Embarrassment as a Signal of Prosociality." Journal of Personality and Social Psychology 102:81-97. http://dx.doi.org/10.1037/a0025403

Feld, Scott. 1982. "Social Structural Determinants of Similarity among Associates." American Sociological Review 47:797-801. http://dx.doi .org/10.2307/2095216

Fetchenhauer, Detlef, and David Dunning. 2006. "Perceptions of Prosociality and Solidarity in Self and Others." Pp. 225-242 in Solidarity and Prosocial Behavior edited by Detlef Fetchenhauer, Andreas Flache, Abraham P. Buunk, and Siegwart Lindeberg. New York: Springer US. http://dx. doi .org/10.1007/0-387-28032-4_4

Fetchenhauer, Detlef, and David Dunning. 2009. “Do People Trust Too Much or Too Little?" Journal of Economic Psychology 30:263-276. http://dx. doi .org/10.1016/j . joep. 2008. 04.006

Fetchenhauer, Detlef, Ton Groothuis, and Julia Pradel. 2010. “Not Only States but Traits: Humans Can Identify Permanent Altruistic Dispositions in 20 Seconds." Evolution and Human Behavior 31:80-86. http: //dx. doi .org/10.1016/j . evolhumbehav . 2009.06.009

Frank, Robert H. 1988. Passions within Reason: The Strategic Role of the Emotions. New York: W.W. Norton \& Company.

Frank, Robert H., Thomas Gilovich, and Dennis T. Regan. 1993. "The Evolution of One-Shot Cooperation: An Experiment." Ethology and Sociobiology 14:247-256. http://dx.doi .org/ 10.1016/0162-3095(93) 90020-I

Green, Leonard, and Joel Myerson. 2004. "A Discounting Framework for Choice with Delayed and Probabilistic Reward." Psychological Bulletin 130:769-792. http://dx.doi. org/10.1037/0033-2909.130.5.769

Haley, Kevin J., and Daniel M.T. Fessler. 2005. "Nobody's Watching? Subtle Cues Affect Generosity in an Anonymous Economic Game." Evolution and Human Behavior 26:245-256. http://dx.doi.org/10.1016/j.evolhumbehav.2005.01.002

Haselton, Martie G., and David C. Funder. 2006. "The Evolution of Accuracy and Bias in Social Judgment." Pp. 16-37 in Evolution and Social Psychology edited by Mark Schaller, Jeffry A. Simpson, and Douglas T. Kenrick. New York: Psychology Press.

Hoffman, Elizabeth, Kevin McCabe, and Vernon L. Smith. 1996. "Social Distance and Other Regarding Behavior in Dictator Games." The American Economic Review 86:653-680.

Kahneman, Daniel, and Amos Tversky. 1979. "Prospect Theory: An Analysis of Decisions under Risk." Econometrica 47:263-291. http://dx.doi .org/10.2307/1914185

Kenny, David A., and Linda Acitelli. 2001. "Accuracy and Bias in the Perception of the Partner in a Close Relationship." Journal of Personality and Social Psychology 80:439-448. http://dx.doi.org/10.1037/0022-3514.80.3.439

Kovács-Bálint, Zsófia, Tamás Bereczkei, and István Hernádi. 2013. “The Telltale Face: Possible Mechanisms Behind Defector and Cooperator Recognition Revealed by Emotional Facial Expression Metrics." British Journal of Psychology 104:563-576.

Kristof-Brown, Amy, Murray R. Barrick, and Cynthia Kay Stevens. 2005. “When Opposites Attract: A Multi-Sample Demonstration of Complementary Person-Team Fit on Extraversion." Journal of Personality 73:935-958. http://dx.doi.org/10.1111/j. $1467-6494.2005 .00334 . x$

Krueger, Joachim, and Russell W. Clement. 1994. "The Truly False Consensus Effect: An Ineradicable and Egocentric Bias in Social Perception." Journal of Personality and Social Psychology 67:596-610. http://dx.doi.org/10.1037/0022-3514.67.4.596 
Macy, Michael W., and John Skvoretz. 1998. "The Evolution of Trust and Cooperation between Strangers: A Computational Model." American Sociological Review 63:638-660. http://dx.doi.org/10.2307/2657332

Madden, Gregory J., Andrea M. Begotka, Bethany R. Raiff, and Lana L. Kasten. 2003. “Delay Discounting of Real and Hypothetical Rewards." Journal of Experimental and Clinical Psychopharmacology 11:139-145. http://dx.doi .org/10.1037/1064-1297.11.2.139

Manson, Joseph H., Matthew M. Gervais, and Michelle A. Kline. 2013. “Defectors Cannot Be Detected during 'Small Talk' with Strangers." PloS ONE 8:e82531. http://dx. doi .org/ 10.1371/journal.pone.0082531

Mashek, Debra J., Arthur Aron, and Maria Boncimino. 2003. "Confusions of Self with Close Others." Personality and Social Psychology Bulletin 29:382-392. http://dx.doi.org/10. $1177 / 0146167202250220$

McPherson, Miller, Lynn Smith-Lovin, and James M. Cook. 2001. “Birds of a Feather: Homophily in Social Networks." Annual Review of Sociology 27:415-444. http://dx . doi . org/10.1146/annurev.soc.27.1.415

Nettle, Daniel, Zoe Harper, Adam Kidson, Rosie Stone, Ian S. Penton-Vodak, and Melissa Bateson. 2013. "The Watching Eyes Effect in the Dictator Game: It's Not How Much You Give, It's Being Seen to Give Something." Evolution and Human Behavior 34:35-40. http://dx.doi.org/10.1016/j.evolhumbehav.2012.08.004

Oda, Ryo, Noriko Yamagata, Yuki Yabiku, and Akiko Matsumoto-Oda. 2009. "Altruism Can Be Assessed on Impression." Human Nature 20:331-341. http://dx.doi .org/10.1007/ s12110-009-9070-8

Parks, Craig D., and Ann C. Rumble. 2001. "Elements of Reciprocity and Social Value Orientation." Personality and Social Psychology Bulletin 27:1301-1309. http://dx. doi .org/ $10.1177 / 01461672012710006$

Peck, Joel. 1992. "Group Selection, Individual Selection and the Evolution of Genetic Drift." Journal of Theoretical Biology 159:163-187. http://dx. doi .org/10.1016/S0022-5193(05) 80700-3

Pierce, Gregory R., Irwin G. Sarason, Barbara R. Sarason, Jessica A. Solky-Butzel, and Lauren C. Nagle. 1997. “Assessing the Quality of Personal Relationships.” Journal of Social and Personal Relationships 14:339-356. http://dx.doi.org/10.1177/0265407597143004

Pradel, Julia, Harald A. Euler, and Detlef Fetchenhauer. 2009. "Spotting Altruistic Dictator Game Players and Mingling with Them: The Elective Assortation of Classmates." Evolution and Human Behavior 30:103-113. http://dx.doi.org/10.1016/j . evolhumbehav . 2008.09 .003

Rachlin, Howard, A. W. Logue, John Gibbon, and Marvin Frankel. 1986. "Cognition and Behavior in Studies of Choice." Psychological Review 93:33-45. http://dx. doi.org/10. 1037/0033-295X.93.1.33

Raineri, Andres, and Howard Rachlin. 1993. "The Effect of Temporal Constraints on the Value of Money and Other Commodities." Journal of Behavioral Decision Making 6:77-94. http://dx.doi.org/10.1002/bdm.3960060202

Rigdon, Mary, Keiko Ishii, Motoki Watabe, and Shinobe Kitayama. 2009. “Minimal Social Cues in the Dictator Game." Journal of Economic Psychology 30:358-367. http://dx. doi . org/10.1016/j.joep.2009.02.002

Ross, Lee, David Greene, and Pamela House. 1977. “The 'False Consensus' Effect: An Egocentric Bias in Social Perception and Attribution Processes." Journal of Experimental Social Psychology 13:279-301. http://dx. doi .org/10.1016/0022-1031 (77) 90049-X 
Rusbult, Caryl E., and Paul A.M. Van Lange. 2003 "Interdependence, Interaction and Relationships." Annual Review of Psychology 54:351-75. http://dx.doi .org/10.1146/ annurev.psych.54.101601.145059

Schul, Yaacov, and Amiram D. Vinokur. 2000. "Projection in Person Perception among Spouses as a Function of the Similarity in Their Shared Experiences." Personality and Social Psychology Bulletin 26:987-1001. http://dx . doi .org/10.1177/01461672002610008

Sheldon, Kennon M., Melanie Skaggs Sheldon, and Richard Osbaldiston. 2000. "Prosocial Values and Group Assortation." Human Nature 11:387-404. http://dx.doi.org/10. $1007 /$ s12110-000-1009-z

Simpson, Brent, and Robb Willer. 2008. "Altruism and Indirect Reciprocity: The Interaction of Person and Situation in Prosocial Behavior." Social Psychology Quarterly 71:37-52. http://dx.doi.org/10.1177/019027250807100106

Simpson, Brent, Matthew Brashears, Eric Gladstone, and Ashley Harrell. 2014. "Birds of Different Feathers Cooperate Together: No Evidence for Altruism Homophily in Networks." Sociological Science 1:542-564. http://dx.doi.org/10.15195/v1 . a30

Sober, Elliott, and David Sloan Wilson. 1988. Unto Others: The Evolution and Psychology of Unselfish Behavior. Cambridge, MA: Harvard University Press.

Sparks, Adam, Tyler Burleigh, and Pat Barclay. 2016. “We Can See Inside: Accurate Prediction of Prisoner's Dilemma Decisions in Announced Game Following a Face-to-Face Interaction." Evolution and Human Behavior. 37:210-216. http://dx.doi .org/10.1016/j . evolhumbehav.2015.11.003

Trivers, Robert L. 1971. "The Evolution of Reciprocal Altruism." The Quarterly Review of Biology 46:35-57. http://dx.doi.org/10.1086/406755

Van Lange, Paul A.M. 1999. “The Pursuit of Joint Outcomes and Equality in Outcomes: An Integrative Model of Social Value Orientation." Journal of Personality and Social Psychology 77:337-349. http://dx.doi.org/10.1037/0022-3514.77.2.337

Van Lange, Paul A.M., Anthon Klapwijk, and Laura M. Van Munster. 2011. "How the Shadow of the Future Might Promote Cooperation." Group Processes E Intergroup Relations 14:85770. http://dx.doi.org/10.1177/1368430211402102

Verplaetse, Jan, Sven Vanneste, and Johan Braeckman. 2007. “You Can Judge a Book by its Cover: The Sequel. A Kernel of Truth in Predictive Cheating Detection." Evolution and Human Behavior 28:260-271. http://dx.doi.org/10.1016/j . evolhumbehav 2007. 04.006

Vogt, Sonja, Charles Efferson, and Ernst Fehr. 2013. “Can We See Inside? Predicting Strategic Behavior Given Limited Information." Evolution and Human Behavior 34:258-264. http://dx.doi.org/10.1016/j.evolhumbehav.2013.03.003

Warner, Rebecca M., David A. Kenny, and Michael Stoto. 1979. “A New Round Robin Analysis of Variance for Social Interaction Data." Journal of Personality and Social Psychology 37:1742-1757. http://dx.doi.org/10.1037/0022-3514.37.10.1742

Wilson, David Sloan, and Lee A. Dugatkin. 1997. "Group Selection and Assortative Interactions." The American Naturalist 149:336. http://dx.doi.org/10.1086/285993

Yamagishi, Toshio, Masako Kikuchi, and Motoko Kosugi. 1999a. "Trust, Gullibility and Social Intelligence." Asian Journal of Social Psychology 2:145-161. http://dx. doi .org/10. $1111 / 1467-839 x .00030$

Yamagishi, Toshio, Nobuhito Jin, and Toko Kiyonari. 1999b. "Bounded Generalized Reciprocity: Ingroup Boasting and Ingroup Favoritism." Advances in Group Processes, 16:161197. 
Yamagishi, Toshio, Shigehito Tanida, Rie Mashima, Eri Shimoma, and Satoshi Kanazawa. 2003. "You Can Judge a Book by its Cover: Evidence that Cheaters May Look Different from Cooperators." Evolution and Human Behavior 24:2. http://dx.doi .org/10.1016/ S1090-5138(03) 00035-7

Acknowledgements: I would like to thank Brent Simpson, Jeffrey Wagner, Audrey Smerbeck, John Edlund, and Gregory DeAngelo for their comments and suggestions on earlier drafts of the paper. Jesper Sørensen made suggestions that were incorporated in the final version of the manuscript. Yosef Boutakov and Matthew Kehoe assisted with data collection. Jonathan Stone assisted with data collection in the pilot study.

Michael J. Vernarelli: Department of Economics, Rochester Institute of Technology.

E-mail: mjvgss@rit.edu. 